\title{
IPCC and the Deep Sea: A Case for Deeper Knowledge
}

\author{
Lisa A. Levin* \\ Center for Marine Biodiversity and Conservation and Integrative Oceanography Division, Scripps Institution of Oceanography, \\ University of California, San Diego, San Diego, CA, United States
}

IPCC reporting culture and structure leads to a failure to highlight potential vulnerabilities and risk in areas where research is largely absent. Nowhere is this more obvious than in treatment of the deep ocean (waters below $200 \mathrm{~m}$ ), where climate research is in its infancy, but human exploitation of resources is on the rise. Understanding climate-induced changes in deep- sea environments, ecosystems and their services, including carbon cycling and climate regulation, is fundamental to future ocean sustainability and to decisions about active climate remediation.

Keywords: deep ocean, climate change, biodiversity, SROCC, UN Decade for Ocean Science

\section{OPEN ACCESS}

Edited by:

Matthew Collins,

University of Exeter, United Kingdom

Reviewed by:

Mrinal Biswas,

National Center for Atmospheric

Research (UCAR), United States

Yonggang Liu,

Peking University, China

Laura Lapham,

University of Maryland Center for

Environmental Science (UMCES),

United States

*Correspondence:

Lisa A. Levin

llevin@ucsd.edu

Specialty section:

This article was submitted to

Predictions and Projections,

a section of the journal

Frontiers in Climate

Received: 04 June 2021

Accepted: 23 July 2021

Published: 27 August 2021

Citation:

Levin LA (2021) IPCC and the Deep Sea: A Case for Deeper Knowledge.

Front. Clim. 3:720755.

doi: 10.3389/fclim.2021.720755

\section{INTRODUCTION}

The Intergovernmental Panel on Climate Change (IPCC) reporting system for both the assessment reports (AR) and special reports (SR) provide assessment of climate change, its consequences for ecosystems, the implications for humans and possible solutions. It emphasizes information and topics for which there is a solid scholarly basis for assessment, often interpreted as multiple studies conducted by multiple research groups so that statistical likelihood or confidence language can be applied. The reports are concise, given the huge breadth of topics covered, thus text gets whittled down to meet stringent page limits, and summaries for policy makers (SPM) focus on conclusions with medium or high confidence. Under the auspices of IPCC Working Group 2 (Impacts, Adaptation and Vulnerability), I participated as one of many lead authors in preparation of the Special Report on Oceans and Cryosphere in a Changing Climate (SROCC), as a contributing author for AR5 and as a review editor for AR6. What these reports are not able to do is highlight potential vulnerabilities and risk in areas where research is largely absent. Nowhere is this more obvious than in treatment of the deep ocean (waters below $200 \mathrm{~m}$ ).

\section{DELVING DEEPER}

Despite the fact that the deep ocean covers nearly half the planet's surface (and most of the habitable volume), and absorbs massive amounts of heat and carbon dioxide, direct observations of the consequences of climate change for modern deep-sea ecosystems are sparse (Levin and Le Bris, 2015; Sweetman et al., 2017). Nevertheless, earth system model outputs indicate that deep waters are warming, becoming more acidic, and loosing oxygen and that this trend will continue in the future under all emission reduction scenarios (Bindoff et al., 2019; Kwiatkowski et al., 2020). The projected consequences include species and productivity redistributions, habitat compression, biodiversity loss, and changes in body size, food webs and connectivity that can influence commercial harvest, carbon sequestration and nutrient cycling (Sweetman et al., 2017; Brito-Morales et al., 2020), but few in situ observations exist that can confirm these. The IPCC AR 5 does not address the deep ocean in detail and AR 6, while hosting two deep-sea subsections, has limited text thus far. The deep sea contains diverse ecosystems with 
different climate vulnerabilities. This emerges from the burning ember diagram in SROCC Ch. 5 (Fig. 5.16 in Bindoff et al., 2019), which notably offers risk assessment for 5 deep-sea ecosystems. But confidence levels are low, and thus three of the five ecosystems are not reflected in the SROCC SPM. Ecosystem heterogeneity in the deep sea is driven by reliance on photovs. chemosynthesis, topographic variation (e.g., canyons, slopes, ridges and seamounts), oligo-vs eutrophic settings, varied water masses and interactions with the epipelagic and mesopelagic realms (Ramirez-Llodra et al., 2010). The deep ocean contains both living and non-living energy and mineral resources of growing interest (Ramirez-Llodra et al., 2011; Mengerink et al., 2014). Despite this, early external reviewers of the SROCC Chapter 5 viewed the deep as one habitat and questioned why the deep "ecosystem" should get more space in the report than single coastal systems such as estuaries, sandy beaches or salt marshes.

The limited information about climate consequences for the deep ocean carries over to AR6. This is evident for example in the fact that open-ocean, deep-sea systems do not feature in the discussion in the AR6 WGII Cross Chapter paper on biodiversity hotspots. The $60 \%$ of the ocean which is deep barely registers in this discussion, despite knowledge of exceedingly high biodiversity (Rex and Etter, 2010), high endemism in settings such as hydrothermal vents and seamounts, and recognized climate vulnerability (Levin and Le Bris, 2015; Sweetman et al., 2017; Bindoff et al., 2019; Brito-Morales et al., 2020). Apparently needed quantification of biodiversity is missing.

Observational programs have generated a reasonable understanding of temperature change in the deep sea and Earth System model projections have been extended to the deep sea floor (Sweetman et al., 2017; Kwiatkowski et al., 2020), so there are now predictions of future seafloor exposures to changing temperature, oxygen, $\mathrm{pH}$ and more, the time of emergence of these signals, and other derived metrics. These can be used to project changes in species distribution or connectivity (e.g., Levin et al., 2020; Morato et al., 2020). But most of the information about faunal response to climate change in the deep ocean comes largely from the study of paleo records, natural gradients, very limited laboratory experimentation (e.g., for cold water corals) and basic biological knowledge of how living systems respond to temperature, rather than from extensive in situ observations over time or from laboratory experiments. There are only a handful of long-term study sites in the deep ocean that are capable of documenting modern ecosystem response to anthropogenic climate change. Those in the Pacific (Station M) and the Atlantic (PAP), exhibit an unanticipated level of temporal variability in ecological attributes that is difficult to attribute to secular climate change (Smith et al., 2013; Hartman et al., 2021). A limited number of observatories now have multi-decadal data, but these monitor just a few types of ecosystems (e.g., Hausgarten, Ocean Networks Canada).

We need distributed observations of environmental change in the deep ocean, faunal responses to this change and the consequences for people (ecosystem services) to better understand the deep ocean and predict the earth climate system. This will guide how we can mitigate and adapt to change, and perhaps introduce a new set of blue carbon solutions (Hilmi et al., 2021). But this is not a main message of the IPCC SROCC, and there is very little about the deep ocean in the summary for policy makers (IPCC, 2019). Much assembled material addressing climate impacts on deep-ocean ecosystems and consequences for ecosystem services was cut or merged, and in a few cases relegated to supplemental material to meet page limits and emphasize known risk in the SROCC (Bindoff et al., 2019). It is probable that similar cuts have occurred for other ecosystems in SROCC and other reports, but it is doubtful that any of those systems cover an area as vast or are as poorly known as the deep ocean.

\section{DISCUSSION}

The IPCC may need to begin producing parallel inverse assessment reports that shine a light on what we don't know but need to know and why, to help guide the efforts of science, scientists and science funders in the coming decade. Such an inverse report might identify the deepsea processes that need to be understood and parameters measured to improve (or groundtruth) climate model predictions and the geographic regions and ecosystems where direct observations would enhance understanding of these processes. It could also highlight additional deep-sea research, technological advances and modeling innovations required for management of resource extraction (e.g., for seabed mining) and biodiversity conservation. Notably, the deep-sea ecosystem subsections of the World Ocean Assessment II (United Nations, 2021) devote considerable attention to knowledge gaps relevant to societal needs. The IPCC could draw on this massive compilation and synthesis to a greater extent.

There is growing attention to the ocean-climate-biodiversity nexus among scientists, but it needs to deepen. The deep sea rarely appears in discussion of integrated strategies to achieve ocean-related climate and biodiversity action synergies. Understanding deep-sea species tolerances and thresholds to climate variables, traits that exacerbate climate vulnerability, the consequences of changing species distributions and interactions, how these translate into altered ecosystem function and the implications for the ecosystem services we rely on, is fundamental. This knowledge can underpin climate adaptation and carbon conservation efforts that maintain carbon sequestration and protect the largely undescribed biodiversity in the face of rising threats from bottom trawling, deep oil and gas extraction and seabed mining. It also may eventually be needed to understand the consequences of different forms of climate intervention or geoengineering. By informing IPCC assessments, UNFCCC Nationally Determined Contributions, Research Dialogues, and the Global Stocktake, deep-sea science can help achieve the goals of the UNFCCC Paris Agreement.

The UN Decade for Ocean Science offers an important opportunity to fill deep-ocean knowledge gaps. A Decade deep sea "community of practice," with programs such as the Deep-Ocean Observing Strategy (Levin et al., 2019) and Challenger 150 (Howell et al., 2021), could generate observations 
and build knowledge needed for sustainable development of the ocean and people under climate change. Such deepocean knowledge might make tractable questions such as: How can natural carbon processes be harnessed to help ameliorate or mitigate climate change? and How can we best manage human activities and emerging industries to maintain these processes? A deeper understanding of the deep ocean will ultimately define what we exploit and what we protect.

\section{REFERENCES}

Bindoff, N. L., Cheung, W. W. L., Kairo, J. G., Arístegui, J., Guinder, V. A., Hallberg, R., et al. (2019). "Changing ocean, marine ecosystems, and dependent communities," in IPCC Special Report on the Ocean and Cryosphere in a Changing Climate. Intergovernmental Panel on Climate Change, eds H.-O. Pörtner, D. C. Roberts, V. Masson-Delmotte, P. Zhai, M. Tignor, E. Poloczanska, et al., 477-587.

Brito-Morales, I., Schoeman, D. S., Molinos, J. C., Burrows, M. T., Klein, C. J., Arafeh-Dalmau, N., et al. (2020). Climate velocity reveals increasing exposure of deep-ocean biodiversity to future warming. Nat. Clim. Change 10, 576-581. doi: 10.1038/s41558-020-0773-5

Hartman, S. E., Bett, B. J., Durden, J. M., Henson, S., Iversen, M., Jeffreys, R., et al. (2021). Enduring science: three decades of observing the Northeast Atlantic from the Porcupine Abyssal Plain Sustained Observatory (PAP-SO). Prog. Oceanogr. 191:102508. doi: 10.1016/j.pocean.2020.102508

Hilmi, N. J., Chami, R., Sutherland, M. D., Hall-Spencer, J. M., Lebleu, L., Benitez, M. B., et al. (2021). The role of Blue Carbon in climate change mitigation and carbon stock conservation. Front. Clim. doi: 10.3389/fclim.2021.710546

Howell, K. L., Hilário, A., Allcock, A. L., Bailey, D., Baker, M., Clark, M. R., et al. (2021). A decade to study deep-sea life. Nat. Ecol. Evol. 5, 265-267. doi: $10.1038 / \mathrm{s} 41559-020-01352-5$

IPCC (2019). "Summary for policymakers," in IPCC Special Report on the Ocean and Cryosphere in a Changing Climate, eds H.-O. Pörtner, D. C. Roberts, V. Masson-Delmotte, P. Zhai, M. Tignor, E. Poloczanska, et al.

Kwiatkowski, L., Torres, O., Bopp, L., Aumont, O., and Chamberlain, M. (2020). Twenty-first century ocean warming, acidification, deoxygenation, and upper-ocean nutrient and primary production decline from CMIP6 model projections. Biogeosciences 17, 3439-3470. doi: 10.5194/bg-17-3439-2020. hal-02890864

Levin, L. A., Bett, B. J., Gates, A. R., Heimbach, P., Howe, B. M., Janssen, F., et al. (2019). Global observing needs in the deep ocean. Front. Marine Sci. 6:241. doi: 10.3389/fmars.2019.00241

Levin, L. A., and Le Bris, N. (2015). Deep oceans under climate change. Science 350, 766-768. doi: 10.1126/science.aad0126

Levin, L. A., Wei, C. L., Dunn, D. C., Amon, D. J., Ashford, O. S., Cheung, W. W. L., et al. (2020). Climate change considerations are fundamental to management of deep-sea resource extraction. Global Change Biol. 26, 4664-4678. doi: 10.1111/gcb.15223

Mengerink, K. J., Van Dover, C. L., Ardron, J., Baker, M., Escobar-Briones, E., Gjerde, K., et al. (2014). A call for deep-ocean stewardship. Science 344, 696-698. doi: 10.1126/science. 1251458

\section{DATA AVAILABILITY STATEMENT}

The original contributions presented in the study are included in the article/supplementary material, further inquiries can be directed to the corresponding author/s.

\section{AUTHOR CONTRIBUTIONS}

LL originated and wrote the manuscript.

Morato, T., González-Irusta, J. -M., Dominguez-Carrió, C., Wei, C. -L., Davies, A., Sweetman, A. K., et al. (2020). Climate-induced changes in the suitable habitat of cold-water corals and commercially important deep-sea fishes in the North Atlantic. Global Change Biol. 26, 2181-2202. doi: 10.1111/gcb. 14996

Ramirez-Llodra, E., Brandt, A., Danovaro, R., Escobar, E., German, C. R., Levin, L. A., et al. (2010). Deep, diverse and definitely different: unique attributes of the world's largest ecosystem. Biogeosciences 7, 2851-2899. doi: 10.5194/bg-7-2851-2010

Ramirez-Llodra, E., Tyler, P. A., Baker, M. C., Bergstad, O. A., Clark, M. R., Escobar, E., et al. (2011). Man and the last great wilderness: Human impact on the deep sea. PLOS ONE 6:e22588. doi: 10.1371/journal.pone.002 2588

Rex, M. A., and Etter, R. J. (2010). Deep-Sea Biodiversity: Pattern and Scale. Cambridge: Harvard University Press.

Smith, K. L., Ruhl, H. A., Kahru, M., Huffard, C. L., and Sherman, A. D. (2013). Deep ocean communities impacted by changing climate over $24 \mathrm{y}$ in the abyssal northeast Pacific Ocean. PNAS 110, 19838-19841. doi: $10.1073 /$ pnas. 1315447110

Sweetman, A. K., Thurber, A. R., Smith, C. R., Levin, L. A., Mora, C., Wei, C. L., et al. (2017). Major impacts of climate change on deep seafloor ecosystems. Elementa 5:4. doi: 10.1525/elementa.203

United Nations (2021). The Second World Ocean Assessment: World Ocean Assessment II, vols. I and II (New York, NY).

Conflict of Interest: The author declares that the research was conducted in the absence of any commercial or financial relationships that could be construed as a potential conflict of interest.

Publisher's Note: All claims expressed in this article are solely those of the authors and do not necessarily represent those of their affiliated organizations, or those of the publisher, the editors and the reviewers. Any product that may be evaluated in this article, or claim that may be made by its manufacturer, is not guaranteed or endorsed by the publisher.

Copyright (c) 2021 Levin. This is an open-access article distributed under the terms of the Creative Commons Attribution License (CC BY). The use, distribution or reproduction in other forums is permitted, provided the original author(s) and the copyright owner(s) are credited and that the original publication in this journal is cited, in accordance with accepted academic practice. No use, distribution or reproduction is permitted which does not comply with these terms. 